\title{
Differences in Blood Loss According to Hemostatic Method in the Excision of Giant Neurofibroma
}

\author{
Tae-Gon Kim, Il-Kug Kim, Sung-Eun Kim, \\ Yong-Ha Kim, Jun-Ho Lee \\ Department of Plastic and Reconstructive Surgery, Yeungnam \\ University College of Medicine, Daegu, Korea \\ Correspondence: Tae-Gon Kim \\ Department of Plastic and Reconstructive Surgery, Yeungnam University \\ Medical Center, Yeungnam University School of Medicine, 170 Hyeonchung- \\ ro, Nam-gu, Daegu 705-717, Korea \\ Tel: +82-53-620-3480, Fax: +82-53-626-0705 \\ E-mail: kimtg0919@hanmail.net \\ This work was supported by Yeungnam University grants in 2010. \\ This article was presented at the 69th Congress of the Korean Society of Plastic and \\ Reconstructive Surgeons on November 11-13 2011 in Seoul, Korea. \\ No potential conflict of interest relevant to this article was reported. \\ Received: 16 Feb 2012 • Revised: 27 Apr 2012 • Accepted: 14 May 2012 \\ pISSN: 2234-6163 • elSSN: 2234-6171 \\ http://dx.doi.org/10.5999/aps.2012.39.4.433 • Arch Plast Surg 2012;39:433-434 \\ Copyright (C) 2012 The Korean Society of Plastic and Reconstructive Surgeons \\ This is an Open Access article distributed under the terms of the Creative Commons \\ Attribution Non-Commercial License (http://creativecommons.org/licenses/by-nc/3.0/ \\ which permits unrestricted non-commercial use, distribution, and reproduction in any \\ medium, provided the original work is properly cited.
}

Approximately half of the patients who have neurofibroma also develop vascular deformities and vascular malformations inside the neurofibroma masses [1]. Therefore, there is a high-risk of hemorrhage during surgery. Many methods have been reported for reducing hemorrhage such as hypotensive anesthesia [2], preoperative arterial embolization [3], and vasa vasorum ligation [1]; however, the effectiveness of these methods is questionable. If the neurofibroma mass is localized, the continuous loop-shaped suture ligation procedure [4] will help reduce the bleeding. We report our experience with reducing hemorrhage by comparing several surgical methods for hemostasis in extensive giant neurofibromas.

A 69-year-old female patient presented with extensive giant neurofibromas throughout her body and massive neurofibromas on her buttocks and thighs, along with aggravating lower back pain, difficulty in walking, and mood disorder. The dimensions of the 
mass were $50 \times 50 \times 16 \mathrm{~cm}$ and it covered most of the patient's lower extremities (Fig. 1). The patient's weight was $67 \mathrm{~kg}$. A preoperative pelvic magnetic resonance imaging was performed and there was no sign of malignancy, hematoma, or necrosis. There was neither skin ulcer nor skin necrosis.

During the first operation, we used Bovie electrocautery (ValleyLab, Boulder, CO, USA), bipolar cautery, and hemoclips. However, we stopped the surgery because of massive intraoperative bleeding. The patient received 15 units of packed red blood cells and 5 units of fresh frozen plasma during the transfusion. Subsequently, the authors planned a second-stage operation. During the first operation we resected $10 \mathrm{~kg}$ of weighed mass during a 9 hours and 40 minutes operation. During the second operation we controlled hemorrhage using hemostatic forceps and manual ligature. The total mass resected during the second operation was $13 \mathrm{~kg}$. The patient received 5 units of packed red blood cells intraoperatively and 3 units postoperatively. The second operation time was 9 hours and 15 minutes. Compressive dressings were maintained after the surgery.

The patient's vital signs were hemodynamically stable and there were no complications, such as lymphedema or bleeding; however, wound healing was delayed. A negative pressure wound therapy was helpful for promoting wound healing. Four months after the two operations, the wound was well healed, and the shape of the buttocks and thighs were anatomically appropriate (Fig. 2). The patient's lower back pain also improved and she regained a normal gait.

The authors resected almost the same quantity of tumor mass during each operation from the patient; however, the amount of bleeding during the second operation was much less than that during the first operation. Therefore, we believe that a tedious process of hemostasis using hemostatic forceps and manual ligature was more effective than electrocautery for reducing hemorrhage during surgery.

\section{References}

1. White N, Gwanmesia I, Akhtar N, et al. Severe haemorrhage in neurofibromatoma: a lesson. Br J Plast Surg 2004;57:456-7.

2. Mukherji MM. Giant neurofibroma of the head and neck. Plast Reconstr Surg 1974;53:184-9.

3. Tung TC, Chen YR, Chen KT, et al. Massive intratumor hemorrhage in facial plexiform neurofibroma. Head Neck 1997;19:158-62.

4. Kim JH, Burm JS, Kim YW, et al. Giant neurofibroma on both buttocks. J Korean Soc Plast Reconstr Surg 2009;36:511-4.

Giant neurofibroma on the abdomen, both buttocks, and thighs in a 69 -year-old woman. Note the $50 \times 50 \times 16 \mathrm{~cm}$ sized mass. Anterior and posterior view.

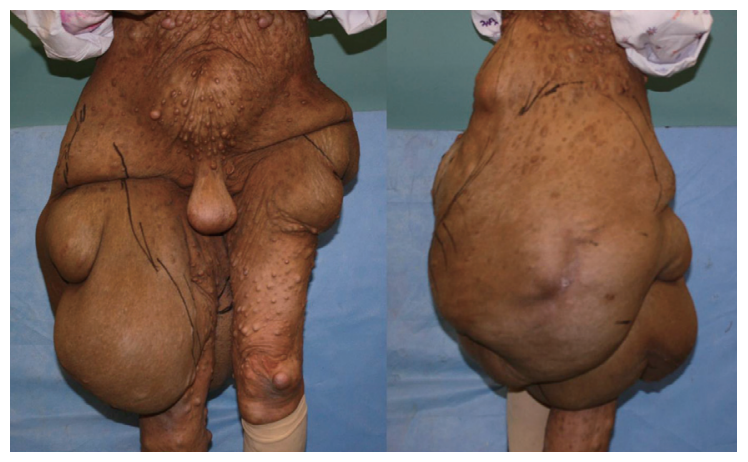

Fig. 2 .

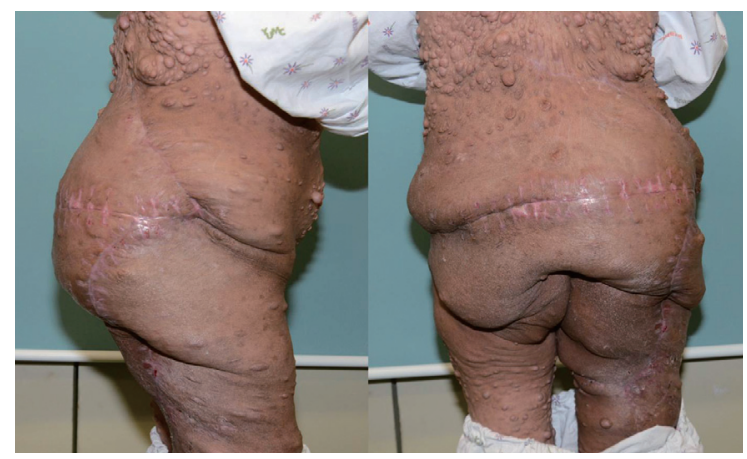

